\title{
The Challenges of Being Ten: Reflections on the Uniqueness of the PfP Consortium
}

\author{
Sean Costigan, Ernst Felberbauer, and Peter Foot*
}

The PfP Consortium is "unique" in the security studies field. But might that uniqueness, embodied in the institution's creation in 1998 - the fiftieth anniversary year of NATO-explain its struggles to see a future for itself as NATO turns sixty?

\section{The Sensorimotor Period: 1998 to $1999^{1}$}

From the start, as was articulated in William Cohen's inaugurating speech at the EuroAtlantic Partnership Council meeting in June 1998, there was newness: "The establishment of a 'Consortium of Defense Academies and Security Studies Institutes' is a contribution to our enhanced Partnership for Peace and, in particular, a means of placing greater emphasis on defense and military education and training - a top priority within the Partnership.",

There were two key elements of freshness here. The first was to emphasize military training as something that could be described as a priority at all. The second was to build on the assumption that military training and education could be improved by being placed in closer proximity to research and policy advice. To that date, defense

Sean S. Costigan is the director for strategic initiatives, North America for the Center for Security Studies, ETH Zurich and a visiting scholar at The New School's graduate program in international affairs. He is chair of the editorial board of the Partnership for Peace Consortium of Defense Academies and Security Studies Institutes and co-chair of the Economics of Terrorism Study Group.

Lt. Col. Ernst M. Felberbauer is Assistant to the Director of DCAF, the Geneva Centre for the Democratic Control of Armed Forces, on secondment from the Directorate General for Security Policy at the Austrian Ministry of Defense. He has been active in the Consortium since 1999, mainly in the Study Group on Regional Stability in South East Europe.

Peter Foot is Academic Dean at the Geneva Centre for Security Policy and Professor Emeritus at the Canadian Forces College Toronto. He has been associated with the work of the Consortium, especially the Editorial Board, for ten years.

Special thanks go to David Law, Senior Fellow at DCAF, who provided input to this paper.

1 The Theory of Cognitive Development, one of the most influential theories in the field of psychology, was developed by Jean Piaget, a Swiss philosopher (1896-1980). The theory concerns the emergence and construction of schemata-schemes of how one perceives the world-in "developmental stages.” The theory is considered "constructivist," meaning that, unlike nativist theories (which describe cognitive development as the unfolding of innate knowledge and abilities) or empiricist theories (which describe cognitive development as the gradual acquisition of knowledge through experience), it asserts that we construct our cognitive abilities through self-motivated action in the world. The theory sets four stages of development, here used as section titles_a mirror of the Consortium.

See https://consortium.pims.org/events/1st-annual-conference-jan-2006. 
academies were largely ignored in the academy, regarded as backwaters enlivened by occasional eddies of research and individual writing brilliance.

With the inauguration of the PfP Consortium, for the first time, an opening was now afforded to defense training centers to look outward, to have the opportunity to internationalize their perspectives and, certainly for staff and war colleges, to harmonize their thinking about the teaching of doctrine for the post-Cold War era with two other groups of thinkers: the civilian worlds of research and diplomacy. One should never forget the earth-shaking moves in global policy that took place in 1989 and 1990 - developments that were bound to have tremendous implications in the security and political realms of the entire EAPC region, which was the Consortium's area of focus. Alongside the many other opportunities it offered-like education, travel, information connectivity, and possibilities for publication - this confluence of a critical mass of researchers, military staff, and diplomats was the truly unique concept of the Consortium. Concrete indications were given through the policy objectives articulated in the statement "Towards a Partnership for the $21^{\text {st }}$ Century: The Enhanced and More Operational Partnership," suggested by the NATO PMSC on PfP and endorsed at the NATO Prague Summit in 1999:

The Consortium's objectives, which might be further defined by its participants, could include: to foster greater academic and educational opportunities within the defense and security community; to encourage high standards for professional military education; to promote cost-effective education through collaborative distance learning and distributed training, such as via the Internet; to expand dialogue, understanding, and cooperation through security-related research in EAPC countries; and to explore complementary relationships with other institutions such as the NATO Defense College.

The striking feature of this departure from the norm was that very few national defense academies showed immediate interest in exploiting these opportunities for international openness. National interests were very rarely the point of representation or involvement. Which begs the question, was the Consortium operating above or parallel to the national interests of its members? While indirect government involvement was perceived to be a strength, this was a challenge for the enterprise from the start. The initial assumption had been that the rules that govern PfP membership would apply to the Consortium. Here is a section from early documentation:

For all concerned, including Allies, funding will operate on the principle of "costs lie where they fall." This means that each nation or joining organization is responsible to pay its own expenses to participate in and benefit from the activities of the Consortium according to its own volition. This could include seconding personnel to form a Secretariat, providing venue and support for an annual conference, participating in the development of a journal, and so forth. ${ }^{3}$

National institutions would, of course, wish to carry out national policy. A given government's priorities would naturally be reflected in the priorities of that govern-

3 Ibid. 
ment's participating organizations. It reflected the prevailing official U.S. attitude that academia exists to further national interests, one of the notions characteristic of the nineteenth-century German educational system that still surprise Europeans when they encounter it in twenty-first century U.S. practice. ${ }^{4}$ Eastern European military institutions were struggling to survive, much less conform to some Western-inspired notion of norms. Those colleges that existed (or had been created) in newly independent states were far more interested in the traditional security agendas followed by supposedly sovereign states, and they took as models those examples that were closest at hand historically. Expectations were raised about transparency that more settled states such as France and the United Kingdom could not possibly accept; yet former Warsaw Pact nations were struggling to conform to even these standards.

Moreover, commandants of national military training and education facilities were naturally protective of the institutions they commanded. Networking was a form of communication that offered greater challenges than anticipated. For a Partner nation, if participation in the Consortium improved its chances of getting U.S. gifts of computers and access to the PfP Information Management System (PIMS), then institutional participation would happen, albeit at a level well below that of the commandant of a training facility. For countries that aspired to NATO membership, the demands of the Membership Action Plan were far more pressing than the more gentle, exploratory, and open-ended work being done within the Consortium. As an incentive to the participation of Partner or candidate countries, money for travel was invariably provided through the Consortium offices. But, even with such inducements, defense academies were much more likely to participate in the annual Conference of Commandants, held under the auspices of the NATO Defense College in Rome and now fully open to PfP countries.

Concerns of this type were brought forward as early as 1998 in the status report concerning the Partnership for Peace Consortium of Defense Academies and Security Studies Institutes presented by Swiss Federal Councilor Adolf Ogi in the defense ministers' session at the meeting of the Euro-Atlantic Partnership Council:

Along the lines of this concept it should be possible to establish a meaningful and unique dialogue of institutes, academies, and alumni in support of an evolving EuroAtlantic security community. The difficulty of this piece is to try and identify how we can convert the current mission of improving training and education into a framework for a policy development organization. ${ }^{5}$

4 Actually, as an example, in the late 1980s and early 1990s, the Führungsakademie in Hamburg existed to serve the separate interests of the German Army, Air Force, and Navy, more or less in that order. "Germany" was a much more distant priority.

5 Adolf Ogi, Head of the Swiss Federal Department of Defense, Civil Protection, and Sports, "Status Report Concerning the Partnership for Peace Consortium of Defense Academies and Security Studies Institutes," presented to the defense ministers' session off the meeting of the Euro-Atlantic Partnership Council, Brussels, 18 December 1998; available at https://consortium.pims.org/status-report-concerning-the-partnership-for-peace-consortiumof-defence-academies-and-security-studies-institutes-english. 


\section{The Preoperational Stage: 2000-2004}

In reality, the Consortium offered much more in the way of opportunities for interaction and exchange, but this was insufficiently appreciated by the countries and their security, political, research, and educational institutions. To that extent, the Consortium's uniqueness did not generate its own reward.

In an entirely unintended expression of uniqueness, only four countries provided financial support. To be sure, countries that have hosted annual conferences for the Consortium have had a sponsorship role for their respective year. But the operating expenses of the Consortium have been borne mostly by the United States and Germany as co-hosts of the Consortium's executive offices at the George C. Marshall Center in Garmisch-Partenkirchen. Switzerland and Austria have also been steady providers of resources, in the form of money, facilities, personnel, expertise, or technology. In the case of each of these four countries, representation and resources came directly from and through government officials or serving military officers. Despite rather intense bureaucratic difficulties in funding Eastern Europeans, the U.S. funded quite a number of participants from the newly independent states of Central and Eastern Europe for travel and accommodation. It was clear, however, that for most of these participants, jealously excluding colleagues from enjoying the same benefits was a higher priority than advertising the advantages to their country now offered by the Consortium. For many NATO and Partner countries, representation was usually one stage removed from departments of state. ${ }^{6}$

In sum, this kind of representational mixture was not designed to produce a gradually increasing level of direct national sponsorship for the Consortium. Although money was spent on similar ventures by governments, it simply never made its way to the Consortium. Wealthy countries spent money and appointed officers on a variety of defense and security issues in cases where an individual government could exert direct influence and claim the credit. The Consortium's very uniqueness precluded this kind of support. Curiously, right at the start of its life, as it emerged from the ISF Zurich conference in 1998 - at the same time the first annual conference of the Consortium-a proposal was made for a fully staffed Consortium Secretariat of thirty international officers on secondment, all working for a "secretary-general." Had this been accepted, one might have seen the kind of cost-sharing arrangement that has been used for decades to support the operation of NATO headquarters and facilities. But the political climate at the time would not support this model, and so the Consortium became a largely U.S.-led affair, based in Garmisch-Partenkirchen, very much dependent on the energy and commitment of its executive director and his ability to sustain support from the Office of the Secretary of Defense in the Pentagon.

Participation levels and management structures were, at times, at odds with the in-

6 France was represented by a retired general already seconded to the Marshall Center; British representation was sponsored by the Swiss; Moscow State University represented Russia; Swedish interests were channeled through an air force general responsible for the annual joint U.S.-Swedish Viking exercises in computer simulations. 
ternationalizing vision of the Consortium. And yet the Consortium showed itself to be a remarkable organization. In the cliché of the day, it most certainly added value: it became a structurally and philosophically unique institution that contributed to multilateral communications and fostered both understanding and concrete opportunities to professionalize the armed forces associated with the PfP and NATO. In a new Europe, where national security think-tanks were proliferating, it was more than simply another security studies institute with a logo, publications, a phone number, and a website. As its series of annual conferences sought to demonstrate, the Consortium was about participation in a revolution of strategic education linked to security research. The ending of the Cold War, the recent years of bloody conflict in the Western Balkans, the development of emerging technologies for distance learning and communication, the wish to integrate militaries fully in newly-emergent, independent states, the (transitory) doctrinal enthusiasm for the Revolution in Military Affairs, the recognition that national training institutions, NATO, or the universities needed to lead in this area-all contributed to the sense that the Consortium had a unique and important role to play on behalf of the Euro-Atlantic community.

Despite the structural impediments discussed above, the Consortium offered a dynamic mix of official and unofficial representation across the EAPC. In its annual meetings, and in small working and study groups, people from uniformed militaries, government, academic institutions, and the security community discussed issues in a context of freedom and openness that rarely exists in policy communities. As one small but pertinent example of the Consortium's early uniqueness, nowhere else could Azeris and Armenians meet in a strictly Chatham House-governed, non-governmental atmosphere that encouraged mutual cooperation and respect.

While not everything was rosy, friendships across any number of recently-fallen borders were quick to develop that gave the Consortium even more strength and vitality. Those friendships provided core strength and heartfelt humor that would later prove to be crucial to the maturation and survival of the Consortium. ${ }^{7}$ The bottom-up organizational structure, can-do attitude, and creative thinking endowed the Consortium with potential and originality. No one else had actively recruited security researchers from Eastern Europe and Central Asia. New scholars were welcomed and became completely equal participants in any group. Historians were as welcome as political scientists and technologists. There was no compartmentalizing of disciplines; innovation and quality were the intended results. At the beginning, there was neither a political hierarchy nor a hierarchy of ideas - an individual or group who wanted Consortium sponsorship for a new area of study had only to convince the Secretariat Working Group of its intellectual and policy viability. Money, the Consortium governing bodies were repeatedly told, was not a constraint.

The result was that, by the fourth annual conference, held in Moscow in 2001, a

7 Indeed, to insert a touch of humor to a serious article, from a 2000 meeting in Rome onwards, members of the Consortium Secretariat Working Group (today the Consortium Steering Committee) fittingly began calling their hard-core dedicated group the "Partnership for Pizza Consortium.” 
vast range of cross-disciplinary subjects were being addressed both at the annual conferences and in more focused gatherings of individual working group meetings in a variety of settings (meetings that were frequently held in Partner countries in order to maximize their inclusion in the security dialogue).

All of this was faithfully representative of the Consortium's mission. But there were also marked limitations, particularly when measured against published output. Publications had been seen from the outset as a vital area for the Consortium to prove its worth. Virtually no academic journal concentrated on the security concerns of Partner nations; NATO enlargement was the theme that was assumed to subsume the range of concerns that confronted these states. The Connections series of publications was designed to meet that evident need. If Europe was again to be whole and secure, the interests of all Europeans had to be understood, not just those of either the NATO family or the bigger powers of Russia and Ukraine to the east. Two weaknesses became apparent almost immediately that severely limited the Consortium's capacity to succeed in this vacant publishing niche. The first was that the standards of writing, research, and information in former Communist countries were low. There were obvious individual exceptions, and they appear regularly in past volumes of the quarterly journal, Connections.

The second limitation was that the working groups - the intellectual engine of Consortium activities-actually produced publishable material in only a minority of cases. ${ }^{8}$ This is not at all to say that no work was done; rather, the point is that the working groups preferred informal discourse and networking to the more stringent requirements of academic publishing. Indeed, this same networking and multilateral, informal outreach remains key to the success of the Consortium.

While networking remains a valued effort, the case persists that tangible products of the discussions of the working groups continue to be in short supply. From the standpoint of generating ideas that lead to publications - a standard measure of success in academia - the Western-based academics who were most heavily involved used the working groups as opportunities to test support for research agendas that were then written up in individually authored, peer-reviewed, Western-oriented journals with established reputations in Western Europe or North America. Thus, the Consortium might have done a better job at exploiting the unique openings in information exchange and dissemination offered by the working groups.

\section{The Concrete Operational Stage: 2005 to Today}

Where the Consortium has been genuinely successful is in serving as host for a variety of activities that, perhaps ironically, did not expressly need the Consortium in order to take place, but have chosen to use it as a vehicle for achieving wider participation, acceptance, and support. This is most obvious in what, ten years on, remains of the working groups:

8 The most notable exceptions were the Western-supported working groups, like the Austrianrun Regional Stability for South East Europe Study Group, or the Swiss-run Security Sector Reform Working Group. 


\begin{tabular}{lcl}
\hline \multicolumn{1}{c}{ Working Group } & Prime Movers & Publishing \\
\hline $\begin{array}{l}\text { Advanced Distributed } \\
\text { Learning }\end{array}$ & U.S. \& Switzerland & Web-based, limited (proceedings) \\
\hline Education Development & U.S. and Canada & Web-based, limited (proceedings) \\
\hline Combating Terrorism & U.S. & $\begin{array}{l}\text { Prolific, U.S.-sponsored or in } \\
\text { Connections quarterly journal }\end{array}$ \\
\hline Security Sector Reform & Switzerland & Prolific, DCAF Geneva \\
\hline $\begin{array}{l}\text { Regional Stability- } \\
\text { Southeast Europe }\end{array}$ & Austria ${ }^{9}$ & $\begin{array}{l}\text { Prolific and sustained, Austrian } \\
\text { Ministry of Defense }\end{array}$ \\
\hline $\begin{array}{l}\text { Regional Stability- } \\
\text { Greater Black Sea Area }\end{array}$ & U.S. & Little so far \\
\hline
\end{tabular}

In every case, the work being done is clearly being sponsored for national reasons: the U.S. Joint Forces Command has a global responsibility to the services of the U.S. military to provide distance education; the Austrian Ministry of Defense follows its national interests in helping to clarify the situation in the Balkans, and is especially generous with publishing; the Geneva Centre for the Democratic Control of Armed Forces still finds it convenient to do SSR work within the framework of the Consortium; and the events of 9/11 imposed terror as an issue for the Consortium to confront, with encouragement from the Bush Administration. ${ }^{10}$ It is not unreasonable to suggest that, in every case identified in the table above, the lead institution involved would be doing exactly what they are doing now, even if the Consortium did not exist.

Clearly, this internal dichotomy both rewards and subverts the Consortium. On the one hand, it provides continuity and purpose, but at a minimal cost to the U.S. exchequer or policy community. On the other hand, it is hardly a ringing endorsement of what is-and still could be-unique about the Consortium. Still, that internal, tensile strength of self-interest is what carried the Consortium through its more troubled second half-decade. It allowed the participants to sustain their commitment to the unique opportunities to further professionalize and prepare the armed forces throughout the Alliance and beyond, and to do so under radically altered and rapidly changing strategic conditions.

That same inner strength also helped Consortium insiders to cope with the internal disappointments that occurred within the organization. The first of these was evident at

9 See https://consortium.pims.org/filestore2/download/2512/letter_of_inten_rs_track_2005.pdf, which is the agreement of 2005 between the Austrian-inspired Regional Security Working Groups for South East Europe, the Caucasus, and Central Asia. In effect, only the South East Europe group still survives. The Greater Black Sea Area Working Group is a new one, with a different operating mandate.

10 Few in the Consortium resisted the idea, but they wanted terrorism to be examined across the working groups, not isolated from other security concerns or debates. 
the 2001 conference in Moscow. This was a huge event-the biggest in the Consortium's history — and the stakes were high. But it was, by almost any standard, a failure. Inspired by good intentions about bringing the new Russia into the Euro-Atlantic family, it was bedeviled by the nomenklatura members who ran the Moscow State University, by Russian determination to make information security (or, rather, counter-espionage through the Internet) the theme of the conference, and by the need of former client states to make much of their newly-found independence. In effect, it became two parallel conferences at loggerheads with each other and, overall, represented a blow to the Consortium, the defining purpose of which had been apparently lost in the melee.

In retrospect, the 2001 conference in Moscow and the 2002 conference in Paris were pivotal events. Both at and after the 2003 conference, which was held in Berlin, nothing was quite the same. A new Director at the Marshall Center faithfully conveyed the Bush Administration's skepticism with vigor and clarity. Met by European incredulity, hostility, or misunderstanding, there was no singularly coherent response from the Consortium in defense of its mission and uniqueness. Used to a more responsive style of U.S. leadership, Europeans within the governing elements of the Consortium were forced back into focusing on their narrow national priorities and/or into sustaining that momentum of activities represented by the institutionally secure working groups and reflected at annual conferences. Numerically, participation by individuals declined, not least through the impact of canceling the 2006 annual conference, which called into question the purpose of the Consortium as an agent of change and security networking. ${ }^{11}$

In parallel, the conflicts in Iraq and Afghanistan were exacting their inevitable price in terms of what was deemed "relevant." In addition, in relative economic and security terms, Central and Eastern Europe were doing fairly well, and history was on the move. A combination of NATO and EU expansion could surely be relied upon to solidify the infrastructure for security and prosperity. Even those who were suspicious about the long-term sustainability of these developments had to concede that things could certainly have been a lot worse. Even in the Balkans, the post-Dayton arrangements were holding. It might have been skin deep; it might have been an illusion, skillfully presented. But it could be offered in government circles as a positive development.

If that most intractable European problem of the Balkans was on its way to a solution, just how much emphasis and resources did the integration of Central and Eastern European states into the Euro-Atlantic family actually now require? It is very hard, given the pressures on military budgets everywhere, to blame politicians and officials for answering that with, "Not as much as we had thought." Unsurprisingly, the Consortium's own answer has been to help provide NATO itself with training assistance in its Partnership Action Plan-Defense Institution Building (PAP-DIB) and Education for Reform programs. This is an institutional survival strategy that appeals particularly to the Consortium's U.S. and German sponsors, and brings to NATO much-needed

11 Originally, the annual conference was the centrepiece of the Consortium's activities, and served as its main operating body. 
training and education expertise. It is a natural evolution in that it reflects the Partnership for Peace as it now is, not as it was at its inception. NATO enlargement has emphasized the special needs of Central Asia, the Caucasus, and the Balkans. In strict constructionist terms, this approach falls within the original mandate of the Consortium. A looser construction would see it as a narrowing and limiting initiative that leaves the Consortium with few attractive options for the long term.

\section{The Formal Operational Stage: Will it be Implemented?}

In the scope of human history, ten years is very little time at all. While Central and Eastern Europe have benefited and, in many cases, thrived, efforts there should be strengthened. The Consortium should be looking to branch out once again, with lessons learned from the past and newly developed abilities retained. While Central Asian nations have suffered setbacks, the Consortium should be ready to work in close concert with them. Indeed, time may show that the Consortium will yet have another unique opportunity.

The agenda of the Consortium needs to be restructured to ensure that the working groups focus on the key issues facing the EAPC region and beyond. Currently this would mean that there would be working groups dedicated to such themes as PAPDIB, regional stability in crisis regions, cooperation with countries of the greater Middle East, relations with the EU and Russia, comprehensive approaches to peace making and conflict management, emerging threats, and others.

The Consortium also needs to rethink its overall objectives. It currently concentrates on networking, training, and outreach, and all these aspects will doubtless remain important to its work. But the Consortium needs an overarching concept to orient its activities. One suggestion would be that it frame itself as a community for policy development, where the emphasis would be on generating workable ideas that can strengthen Euro-Atlantic cooperation and overall effectiveness. This function is chronically underdeveloped at both the governmental and non-governmental levels in many Euro-Atlantic countries, and needs the kind of transnational framework the Consortium could provide. Training and education would remain key dimensions of the Consortium's activities, but would have capacity building for policy development as their core purpose. The Consortium needs to see itself as a results-oriented body that generates ideas and policy proposals for the consideration of a broader audience, both public and governmental.

Henri Matisse once noted in his old age that it had bothered him all his life that he didn't paint like everyone else, and so too it might be for those who have painted this picture of the Consortium. Perhaps the brushstrokes weren't made just right, or the subject matter isn't quite what we had intended. But the picture, on the whole, serves to show what makes the Consortium unique. Openness, dynamism, and vibrancy also have corollaries. Yet, uniqueness, no doubt, has been retained, and is the key to the Consortium's continuing success. 